\title{
Anti-CD22 CAR-expressing T Lymphocytes
}

National Cancer Institute

\section{Source}

National Cancer Institute. Anti-CD22 CAR-expressing T Lymphocytes. NCI Thesaurus.

Code C128556.

A preparation of human T-lymphocytes transduced with a recombinant viral vector encoding a chimeric T-cell receptor (chimeric antigen receptor or CAR) consisting of one or more binding domains targ eting the tumor-associated antigen (TAA) CD22 and fused to one or more co-stimulatory, TCR-signaling domains, with potential immunostimulating and antineoplastic activities. Upon administration, the anti-CD22 CAR-expressing T-lymphocytes, express anti-CD22-CAR on their cell surfaces and bind to the CD22 antigen on tumor cell surfaces. Subsequently, CD22-expressing B-cells are lysed. CD22, a B-lineage-restricted, transmembrane phosphoglycoprotein, is expressed on malignant B-cells. 